\title{
Designed of Pure electric vehicle driving motor and vehicle control system based on DSP and bidirectional $Z$ source inverter
}

\author{
Qing Chen \\ Hunan Railway Professional Technology College, Zhuzhou 412001, China
}

Keywords: Full bridge inverter; SVPWM; DSP.

\begin{abstract}
Based on the space vector pulse width modulation algorithm analysis and research of the digital signal processor generates SVPWM waveform implementation and software algorithms. With the methods used in practice, a digital control three-phase inverter power based on DSP is developed. Relevant test parameters and results show that the design has improved the utilization of the DC voltage, thus making the loss of the switching device smaller. In addition, the closed-loop PI control algorithm is introduced in the inverter power. By the use of the powerful DSP digital signal processing capabilities, the response speed of the system is greatly improved. The system has been tested to achieve $1 \sim 40 \mathrm{~V}$ voltage output regulated with $1 \mathrm{~V}$ step, and $50 \mathrm{~Hz} \sim 1 \mathrm{kHz}$ frequency output modulated with $2 \mathrm{~Hz}$ step. When the output voltage keeps constant at $36 \mathrm{~V}$, its load regulation is less than $5 \%$.
\end{abstract}

\section{Introduction}

The traditional analog power supply there are a lot of inherent defects, with more and higher to the requirement of parameters using environment, unable to meet some features. The rapid development of power electronic technology and digital control technology of the digital three-phase inverter power supply overcame many defects of the traditional analog power supply, make the high quality of inverter power supply has been more and more widely used.

The design of inverter power supply, sine inverter hardware or software methods commonly used control methods. Inherent lack of hardware and implementation of advanced control strategy, which can greatly improve the performance of inverter. The appearance of DSP that makes it possible to inverter adopts a new control method, based on the three-phase full bridge inverter circuit structure, using TMS320F2812 as the control core, completed a three phase variable frequency inverter power supply design. System provides a train of thought, the design of three-phase inverter power supply test showed that the system runs stably, has strong practical value and economic value.

\section{The overall plan}

Three phase variable frequency range of inverter power supply system is composed of four function modules: rectifier circuit, output filter and control circuit based on DSP, and signal feedback circuit. After the transformer rectifier circuit are the after $48 \mathrm{v}$ dc voltage rectifier filtering into stable dc power supply inverter circuit. Inverter circuit is the key to the power supply, its function is to realize the DC/AC power transformation, under the control of the DSP to convert the DC power supply level after the three-phase SPWM waveform supply filter circuit, form a standard sine wave. Inverter control rely mainly on DSP event management modules (EVA and EVB) and A/D conversion module. Provide time have general timer event management module (benchmark), asymmetric/symmetry waveform generator, the four area of the programmable logic control unit, output unit and so on, in order to realize the phase difference of each $120^{\circ}$ three-phase HSPWM wave. And A/D conversion module samples to output the average voltage and converted into digital signals. PI algorithm is used in the process of control. 


\section{The system hardware design}

Uncontrolled rectifier circuit. Using Rectifier Bridge and filter, get relatively stable voltage, circuit is shown in Fig.1.

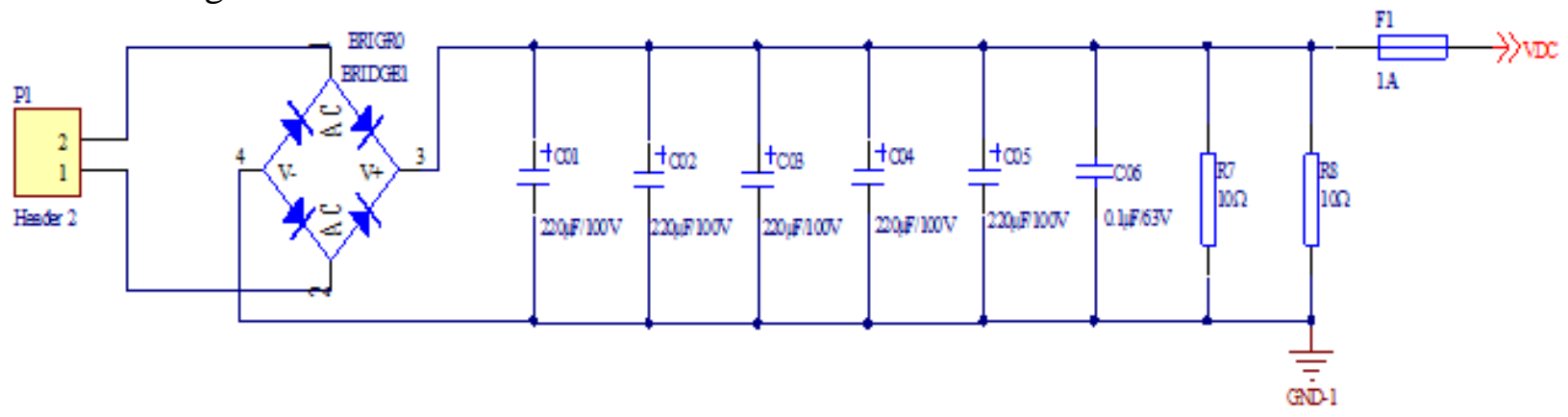

Fig.1. Uncontrolled rectifier circuit diagram

AC - DC conversion circuit. Ac input by the $48 \mathrm{~V}$ transformer will be $220 \mathrm{~V}$ ac voltage transformer for $48 \mathrm{~V}$ input voltage after the ac voltage, and then through the bridge rectifier, again through the capacitor filter, the output size is about $57.6 \mathrm{~V}$ dc voltage. In the indirect a fuse to protect the back of the components, or prevent damage of capacitance when short circuit behind. Used in the design of multiple capacitors in parallel, such flows into each capacitor ripple current is number one in parallel capacitor, each capacitor can work under its maximum rated ripple current flow, here the 5220 (including F capacitance in parallel. Additional typically input filter capacitor and ceramic capacitors (including $0.1 \mathrm{~F}$ ), to absorb the high frequency component of ripple current. Two $20 \mathrm{k}$ resistance bridge behind the role is to make all final capacitor can discharge.

Three-phase bridge rectifier circuit. This module USES the six types of IRF540 MOS tubes in the three-phase bridge type circuit, six bridge Arm Bridge in each arm under the effect of control signal conduction in turn. It is the basic work of $180^{\circ}$ conduction mode, namely each bridge arm of the conduction Angle is $180^{\circ}$, the same phase (i.e., with half bridge) two alternating electric bridge arm, every phase conduction time to start a difference of $120^{\circ}$. Three-phase bridge inverter circuit is shown in Fig. 2.

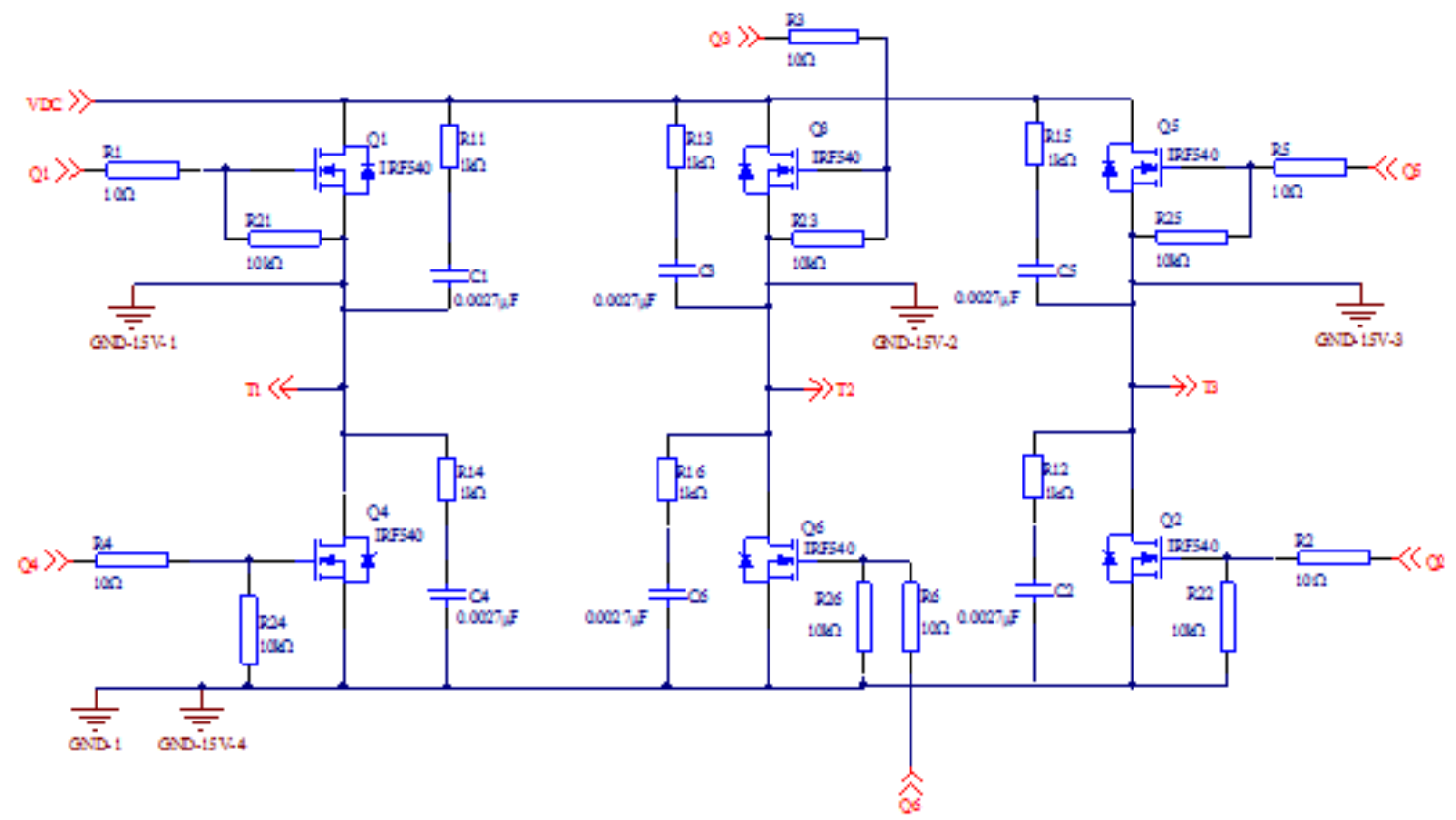

Fig. 2 Three-phase full bridge inverter circuit

Switching speed is between string on the grid in the drive circuit and a resistance to control. If required to compare fast switching speed, resistance don't more than $27 \mathrm{k} \Omega$. Used in the design of 10 $\mathrm{k} \Omega$ resistance. In order to prevent grid dangling out of the question, in the design of the gate electrode 
of the MOS pipe parallel a $10 \mathrm{k} \Omega$ resistance. In parallel in the tube leakage source electrode RC series circuit for absorbing circuit, can further reduce the MOSFET shut off when the peak voltage, the principle of absorbing resistor is at minimum conduction time, still can make the voltage on the capacitor discharge end, the absorption capacity in absorbing resistance power consumption as far as possible big, to the extent permitted by the experiment, the absorbing resistor of the circuit for the $1 \mathrm{k}$, absorption capacity of $0.0027 \mathrm{u} \mathrm{F}$.

Isolated driver circuit. Weak current control system of high voltage, must use the appropriate isolation measures to high voltage side and weaknesses and isolation, heavy current and weak current is realized by using the appropriate driver circuit control. This system in the control side (TMS320F2812) and high voltage isolation end (full bridge inverter circuit) to drive circuit as shown in Fig. 3.

Module design, because the bridge arm up and down the reference point of different voltage and grid voltage of MOS tube, so make sure the gate electrode voltage can reach $15 \mathrm{v}$, just to give each bridge arm TLP250 a $+15 \mathrm{v}$ power supply. Because the point of reference for the same bridge arm under, so the light coupling bridge arm chip can share a power supply; Bridge arm as reference point voltage is higher, and at the same time two gate MOS tube electrode voltage is different, so each MOS tube light coupling chip to a discrete $+15 \mathrm{v}$ dc power supply.

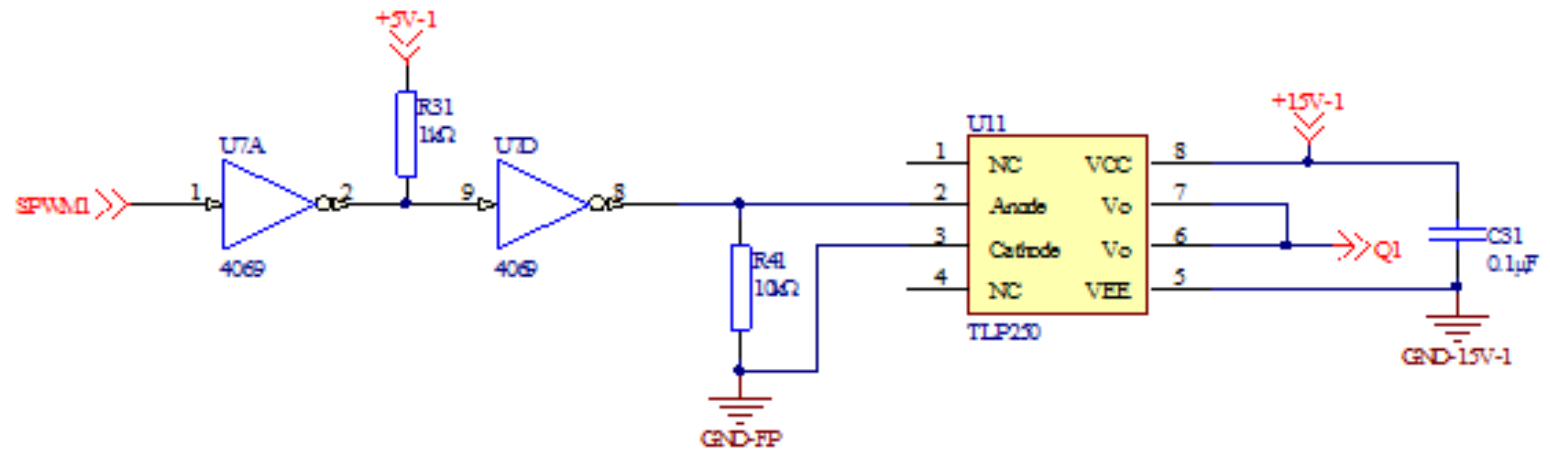

Fig. 3 Isolated driver circuit

Passive filtering and sampling circuit. Influence the design of filter circuit system with load capacity, the three phase filter circuit adopts LC low pass filter, $\mathrm{L}$ and $\mathrm{C}$ value by the method of characteristic impedance and joint calculate the cutoff frequency. The known characteristic impedance

$$
R=\sqrt{\frac{L}{C}}, \quad R_{L}=\frac{V_{O}}{I_{O}}
$$

Take the cutoff frequency $400 \mathrm{~Hz}$, through characteristic impedance method $=(0.5 \sim 0.8)$, namely the $\mathrm{Q}$ value $0.5 \sim 0.8$, the cut-off frequency is $f_{c}=400 \mathrm{~Hz}\left(f_{c}=3 \sim 8 f_{o}\right)$,

$$
f_{c}=\frac{1}{2 \pi \sqrt{L C}} \text {, so } C=\frac{1}{2 \pi R f_{c}}, L=\frac{R}{2 \pi f_{c}} \text {. The system output frequency is } 50 \mathrm{hz} \sim 300 \mathrm{hz} \text {, adjustable }
$$

output voltage is $36 \mathrm{v}$, output current for $1 \sim 3$ a. Compromise between calculation can get $\mathrm{C}=28$ (including $\mathrm{F}, \mathrm{L}=5.5 \mathrm{mH}$ ) USES three specifications for $7748 * * 13$ of yellow core, winding diameter is $1.0 \mathrm{~mm}$, number of turns is about $300 \mathrm{turn}$, get three values of $5.5 \mathrm{mH}$ inductor, capacitor adopts two 10 (including capacitor and a $2.2 \mathrm{~F}$ (including F capacitance in parallel.

Current sampling module adopting the three type of hall current sensor ACS712 chip. The module can measure the positive and negative 20 current and corresponding analog output: $100 \mathrm{mv} / \mathrm{A}$. Circuit shown in Fig.4.

Voltage sampling circuit are done by partial pressure resistance, due to the back of the main circuit and control circuit to isolation, differential amplifier circuit is used to realize, in the design of op-amp using high-performance low noise operational amplifier NE5532. By sampling the maximum voltage of $29.4 \mathrm{~V}$, and the partial pressure resistance to choose two $10 \mathrm{k} \Omega$ and an adjustable $10 \mathrm{k} \Omega$ resistance, the maximum voltage of $9.8 \mathrm{~V}$ after partial pressure. Circuit shown in Fig.5. 


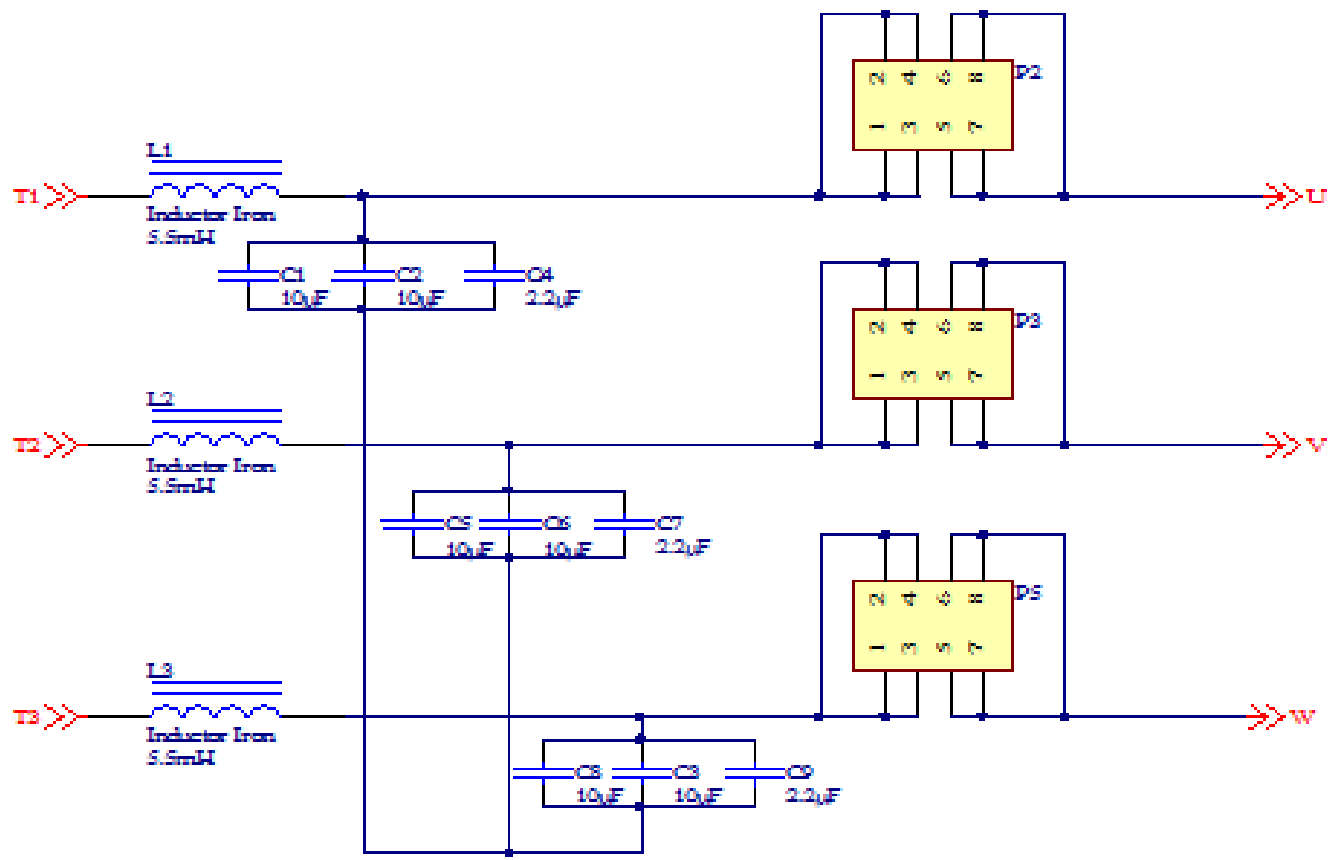

Fig.4 Filtering and current sampling circuit

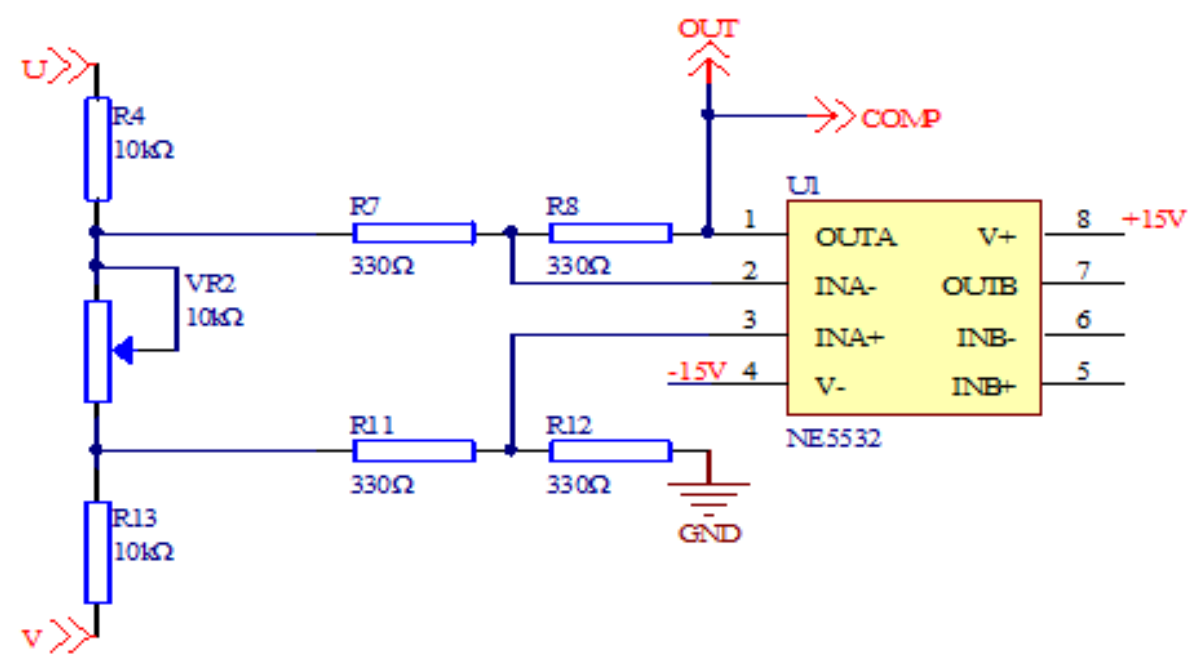

Fig.5. Voltage sampling and differential amplifier circuit

Over voltage protection circuit. This module USES LM311 chip is used in the comparison, the output signal after optical coupling isolation type DSP, and then calculated in DSP processing adjust output SPWM wave. As a result of the test voltage value is bigger, so by partial pressure resistance after partial pressure, and then comparing with the reference voltage. The reference voltage of $2.5 \mathrm{~V}$, provided by the TL431 chip. Sampling the voltage of the maximum theoretical of $51 \mathrm{~V}$, and the partial pressure resistance selection $4.7 \mathrm{k} \Omega$ and $100 \mathrm{k} \Omega$, adjustable test adjust the adjustable resistance when the input to $51 \mathrm{~V}$, the partial pressure of $2.5 \mathrm{~V}$. When sampling $51 \mathrm{v}$ voltage exceed the specified voltage indicator, work light coupling diodes at the same time, the optical coupling produced in the judgment of the trigger signal input to the DSP processing. Over voltage protection circuit are shown in Fig.6. 

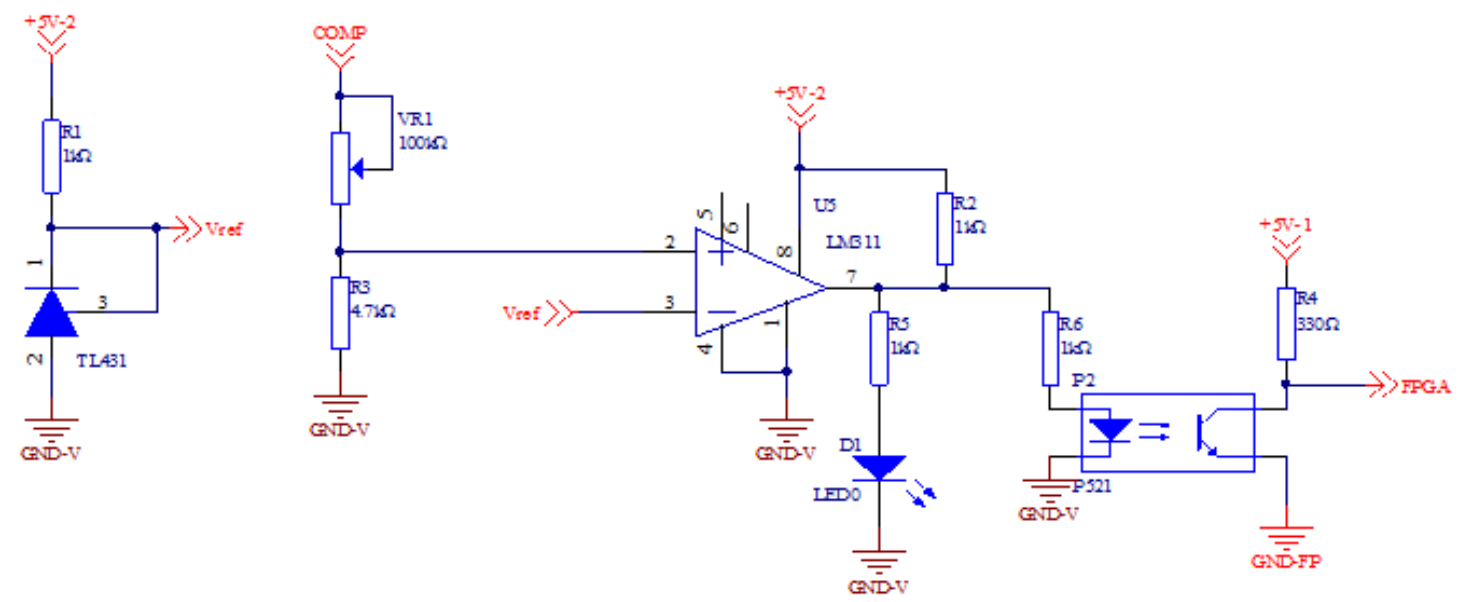

Fig.6 Over voltage protection circuit

\section{Evaluation and conclusion}

Test condition: when the input voltage is $198 \mathrm{v} \sim 242 \mathrm{v}$, the load current effective value is $0.5 \sim 3 \mathrm{~A}$.

Test method: after 500 in front of the isolation transformer v/a from lotus root of transformer, by adjusting the coupling transformer to change the input voltage, the power output of the termination of a $200 \mathrm{w}$ three-phase motors can be started with the resistance, to regulate the output current.

Take frequency $50 \mathrm{~Hz}$, line voltage RMS for $36 \mathrm{v}$. Electrical test, adjust the output voltage of auto transformer, at the same time use the oscilloscope to observe the output. Measurement results as shown in table 1.

Table. 1 Line voltage test results

\begin{tabular}{|c|c|c|c|c|c|c|c|c|c|}
\hline input voltage/V & \multicolumn{3}{|c|}{198} & \multicolumn{3}{c|}{220} & \multicolumn{3}{c|}{36} \\
\hline Valid values/A & 0.58 & 1.5 & 3.0 & 0.58 & 1.5 & 3.0 & 0.58 & 1.5 & 3.0 \\
\hline Uuv/V & 35.22 & 35.85 & 33.71 & 35.30 & 35.67 & 35.80 & 35.43 & 35.73 & 35.65 \\
\hline error/\% & 2.2 & 0.4 & 6.4 & 2.0 & 0.9 & 0.6 & 1.6 & 0.6 & 0.97 \\
\hline Uuw/V & 35.25 & 35.76 & 33.30 & 35.29 & 35.60 & 35.86 & 35.30 & 35.68 & 35.71 \\
\hline error/\% & 2.1 & 0.7 & 7.5 & 2.0 & 1.1 & 0.4 & 1.9 & 0.9 & 0.8 \\
\hline Uvw/V & 35.06 & 35.70 & 33.37 & 35.26 & 35.64 & 35.74 & 35.26 & 35.52 & 35.58 \\
\hline error/\% & 2.6 & 0.8 & 7.3 & 2.1 & 1.0 & 0.7 & 2.1 & 1.3 & 1.2 \\
\hline
\end{tabular}

Results: in the input voltage, under the condition of rather smaller load output line voltage RMS somewhat lower, load regulation, the reason is that the isolation transformer can provide maximum voltage limit, inductance partial pressure loss is bigger.

\section{References}

[1] Ren Xian. Wang Hong. The design and implementation of high-power three-phase inverter power supply based on DSP [J]. Journal of equipment manufacturing technology. 2012 (06): p.175 -178.

[2] Peng-chao zhang. Three-phase inverter power supply based on DSP development [J]. Power technology. 2011, 35(09): p. 1154 -1156.

[3] Lv Fei. Three-phase inverter power supply control research. Master degree theses of master of Harbin industrial university. 2012.

[4] He Tong Neng. A kang. LuFeng. Marine three-phase inverter power supply based on fuzzy PI control research _ [J]. Journal of Zhejiang university of technology 2013, 41(02): p. 222-226

[5] Cao TaiQiang. QiJiang. Wang Jun. The research of control methods of the unbalanced three-phase inverter power supply load [J]. Journal of electrical and control. 2013, 16(04): p. 53-55

[6] Wan Xiao Dong. Li Lan. Dual power supply system for a three-phase inverter power supply [J]. Electric technology. 2012, (10): p. 13-15. 